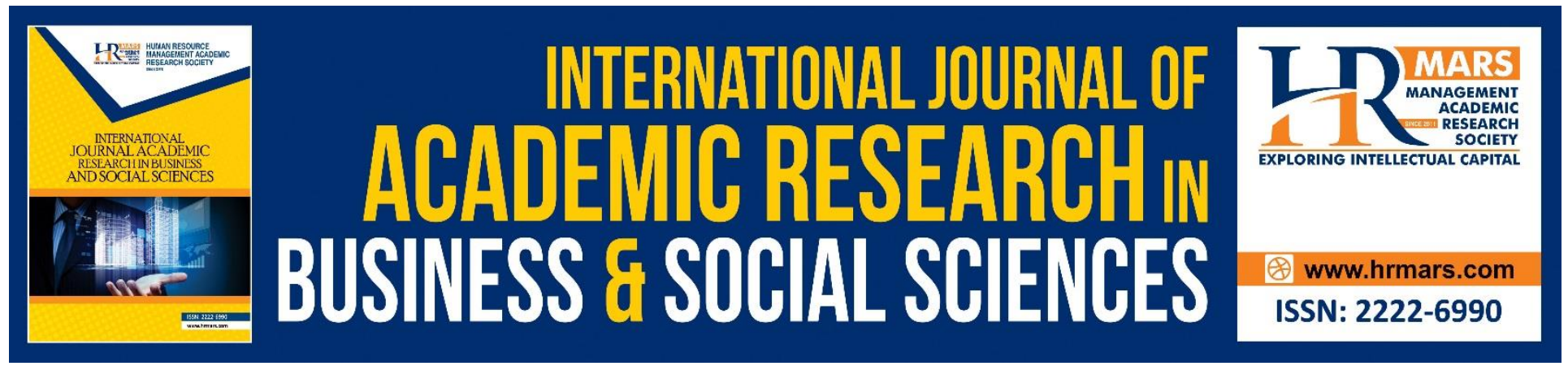

\title{
Internal Control Systems and the Performance of Selected Small and Medium Scale Enterprises in Anambra State
}

\author{
Jonah Charles Tambari, Aginah Chioma, Abara, Chinenye Gladys
}

To Link this Article: http://dx.doi.org/10.6007/IJARBSS/v9-i6/5983

DOI: $10.6007 /$ IJARBSS/v9-i6/5983

Received: 10 April 2019, Revised: 19 May 2019, Accepted: 02 June 2019

Published Online: 24 June 2019

In-Text Citation: (Tambari, Chioma, \& Abara, 2019)

To Cite this Article: Tambari, J. C., Chioma, A., \& Abara, C. G. (2019). Internal Control Systems And The Performance Of Selected Small And Medium Scale Enterprises In Anambra State. International Journal Of Academic Research In Business And Social Sciences, 9(6), 697-706.

Copyright: (C) 2019 The Author(s)

Published by Human Resource Management Academic Research Society (www.hrmars.com)

This article is published under the Creative Commons Attribution (CC BY 4.0) license. Anyone may reproduce, distribute, translate and create derivative works of this article (for both commercial and non-commercial purposes), subject to full attribution to the original publication and authors. The full terms of this license may be seen at: http://creativecommons.org/licences/by/4.0/legalcode

Vol. 9, No. 6, 2019, Pg. 697 - 706

http://hrmars.com/index.php/pages/detail/IJARBSS

JOURNAL HOMEPAGE

Full Terms \& Conditions of access and use can be found at http://hrmars.com/index.php/pages/detail/publication-ethics 


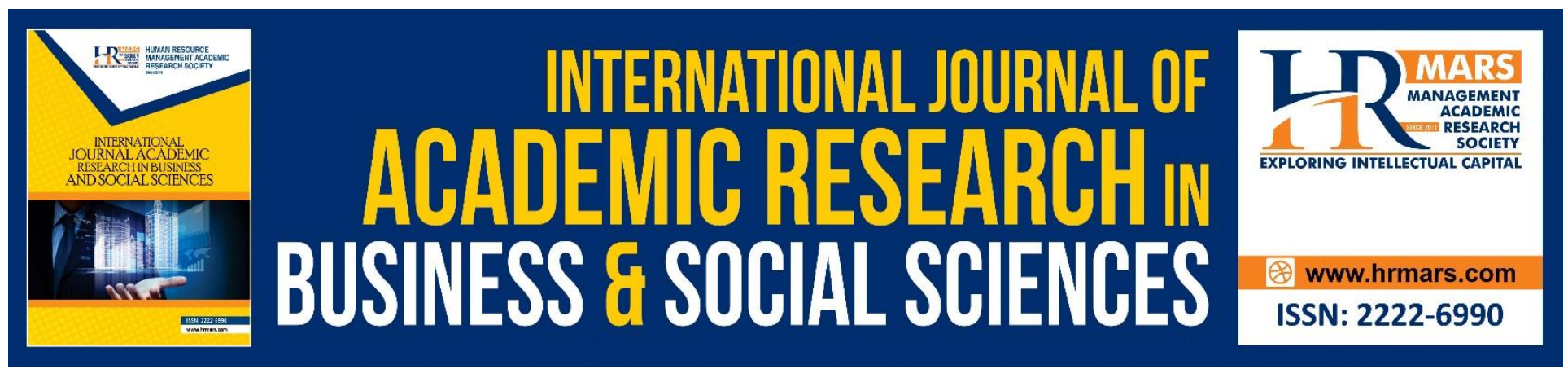

\title{
Internal Control Systems and the Performance of Selected Small and Medium Scale Enterprises in Anambra State
}

\author{
Jonah Charles Tambari \\ Department of Management, Faculty of Management Sciences, University of Portharcourt, Rivers \\ State, Nigeria \\ Aginah Chioma \\ Department of Business Administration and Management, Akanu Ibiam Federal Polytechnic, \\ Unwana, Afikpo, Ebonyi State
}

Abara, Chinenye Gladys

Department of Business Management, Imo State University, Owerri

\begin{abstract}
: the focus of this paper was to investigate the effects internal control system has on the performance of SMEs. Data used in the study was generated majorly from primary source using researchers' designed five point likert scale questionnaire. The study adopted descriptive design and drew its sample from five selected small and medium scale enterprises from the major industrial hubs of Anambra State (Awka, Nnewi and Onitsha). Purposive sampling technique was used to select a sample of 83 members of staff from a combined population of 215 members of staff. The researchers used Mannwhitney Wilcoxon rank test statistical technique with the aid of 23.0 versions of statistical package for social sciences (SPSS) to test the two hypotheses in the study. It was concluded in the study that to generate optimality in resource application which is a sine quanon for enhanced performance, SMEs needs to adopt internal control mechanism that ensures that waste of all sorts (financial and non financial) are reduced to the barest minimum while striving to increase revenue inflow; by so doing they can achieve both operational efficiency and cost leadership which can be boosters to their financial capabilities. From the findings and conclusion above, the paper recommend as follows; SMEs should establish appropriate control environment that takes into cognizance the peculiarities in their industry and that Internal control should be fused into the overall strategies of SMEs, this will facilitate monitoring and prompt reporting of changes in their cost drivers for appropriate managerial decision and actions
\end{abstract}

Keywords: Cost Leadership, Operational Efficiency, Internal Control System 
INTERNATIONAL JOURNAL OF ACADEMIC RESEARCH IN BUSINESS AND SOCIAL SCIENCES Vol. 9, No. 6, June, 2019, E-ISSN: 2222-6990 @ 2019 HRMARS

\section{Introduction}

The operations of most small and medium scale enterprises (SMEs) in Nigeria are often challenged by both external environment induced constraints and constraints associated with poor internal procedures, undefined line of difference between personal and business funds, lack of distinction between ownership and management etc. These challenges and more may have made the complexity in the operations of SMEs intense, cultivated and entrenched role ambiguity thereby given room for abuse of process and other wasteful organizational practices that vitiates the organization's ability to reach its goals. SMEs are therefore beleaguered with the burden to review their operational models in order to meet the needs of their numerous stakeholders. This is the thrust of internal control system. The concept of internal control system emphasizes the need to put the activities of the operators of organizational processes in check so that at all times, their end results will be in alignment with standard procedures as laid down by the management and environmental exigencies. Defining internal control system, Ehiedu and Ogbeta (2014), described it as all measures employed by an organization for the purpose of safe guarding its resources against waste, fraud and inefficiency, promoting accuracy and reliability in accounting and operating data, encouraging and measuring compliance with organizational policy and judging the efficiency of operation in all decision of the business. They further asserted that the system of internal control is much more than a device for the prevention of fraud and dictation of accidental errors in the accounting process, but also as a whole management, internal control embraced internal check and balance established by management. Internal control system defers from organization to organization. They recognized top management decision, the nature of the business, size of the organization and the volume of transactions as critical factors that determines the extent to which the control system is appropriate to the organization.

It is important to state clearly that control systems in the organization are not all about financial. Reid and Ashelby (2002) alluded to this when they posited that internal control is divided into financial internal control and non-financial (administrative) internal control. Financial internal control pertains to financial activities and may be exemplified by controls over company's cash receipts and payments financing operations and company's management of receipts and payments. On the other hand, they defined Non-financial internal control as activities that are indirectly financial in nature i.e. controls over company's personnel section and its operations, fixed assets controls and even controls over laid down procedures. This study will therefore focus on understanding how administrative control system affects non-financial performance of SMEs. Discussing the essence of internal control systems, Amudo and Inanga (2009) posited that a sound internal control system helps an organization to prevent frauds, errors and minimize wastage. Custody of assets is strengthened; it provides assurance to the management on the dependability of accounting data eliminates unnecessary suspicion and helps in maintenance of adequate and reliable accounting records. Mawanda (2008) corroborated the views of Amudo and Inanga by stating that there is a general perception that institution and enforcement of proper internal control systems will always lead to improved financial performance. It is also a general belief that properly instituted systems of internal control improve the reporting process and also give rise to reliable reports which enhances the accountability function of management of an entity. Preparing reliable financial information is a key responsibility of the 
management of every public company. The ability to effectively manage the firm's business requires access to timely and accurate information

In the recent, organizations are leveraging on technology as a key drive in system control. Technologies like close circuit television (CCTV) are installed in workplace environment as both a security measure and as a spy on the activities of the employees. How well this has helped to stop wasteful organizational practices like lateness to work, loafing, indolence, pilferage, report manipulation, expense padding etc has left much to be desired. Moreover, the cost to acquire, install and maintain such technology may create a huge financial burden on the organization. It therefore follows that for SMEs to institutionalize internal control system, they must develop a home grown approach that is consistent with their unique needs. Internal control system covers a wide range of activities which SMEs must strive to integrate, these according to Rick $(2005$,$) are; the Control$ Environment which is an environment or culture where control is recognized and emphasized, Risk Assessment which emphasizes the establishment of policies and procedures for risk assessment, Control activities which is concerned with the recognition that all activities require some measure of control. Others are; Accounting, Information Technology which explains the institution of accounting, information and communication systems and Monitoring which has to do with the establishment of policies and procedures for self-assessment.

Performance is a concept that has received wide attention from researchers. However, what constitute performance for one organization may not necessarily mean performance to another organization. Therefore as much as the concept of performance is widely acknowledged by management and organizational researchers, it is safe to say that it is a relative construct. Its relativity may also have led to its classification into two broad areas i.e financial and non-financial performance areas. Performance therefore concerned with the ability of a firm to conduct its business in an efficient and profitable manner while sustainably surviving environmental changes.

\section{Statement of the Problem}

Internal control system is very key to the creative and efficient management of an organization. Internal control system sees to it that roles are clearly defined, assigned, monitored and evaluated in absence of which the organization may run into role conflict that may reduce employees' productivity, lead to negative work behavior and even personality clashes that can cause outright sabotage to a group effort. Again, part of the wasteful organizational practices that affects the ability of organizations to deliver on their goals is expense padding by staff members. This over bloats the operational cost of the organization thereby place the organization in a disadvantaged position that denies them cost leadership and may even lead to pricing their product out of the market. Finally, lack of a robust internal control system may lead to the destruction of intangible organizational assets like reputation which is one of the drivers of a firm's competitiveness. It can also lead to destruction of tangible asset which may lead to high cost of managing industrial accidents. This paper therefore is faced with the challenge of examining the effects internal control systems has on the performance of selected small and medium scale enterprises. 
INTERNATIONAL JOURNAL OF ACADEMIC RESEARCH IN BUSINESS AND SOCIAL SCIENCES

Vol. 9, No. 6, June, 2019, E-ISSN: 2222-6990 @ 2019 HRMARS

\section{Objectives of the Study}

The broad objective of this paper is to examine internal control systems and the performance of selected small and medium scale enterprises. Its specific objectives are;

i. To examine the effects of internal control system on the operational efficiency of SMEs

ii. To examine the effects of internal control system on the cost leadership of SMEs

\section{Research Questions}

i. To what extent does internal control system have effects on the operational efficiency of SMEs?

ii. How does internal control system affect the cost leadership of SMEs?

\section{Research Hypotheses}

$H_{01}$ : Internal control system does not have significant effect on the operational efficiency of SMEs

$\mathbf{H}_{\mathbf{0 2}}$ : Internal control system does not have significant effect on cost leadership of SMEs

\section{Review of Related Literatures}

The concept of internal control means different things to different people, this may be as a result of professional orientation or result the internal control system is targeted at achieving. However, the core of it all is to enable organizations optimize resources by avoiding wastefulness and where they occur, detect and correct them promptly for the purpose of generating accurate and reliable data for management/business decisions. Schroy (2010) define internal control as the process affected by an organization's structure, work and authority flows, people and management information systems, designed to help the organization accomplish specific goals or objectives\|. He added that it is a means by which an organizations resources are directed, monitored, and measured; and plays an important role in preventing and detecting fraud and protecting the organization's resources, both physical (for instance, machinery and property) and intangible (reputation or intellectual property such as trade mark). In the view of Ravinder and Virender (2005), Internal Control implies the whole system of control employed by the management in order to carry on the business of the enterprise in an orderly and efficient way by having an automatic check and balance overall the transactions. It includes internal check, internal audit and other devices of control. Internal control system assures the management that the information it receives is both reliable and accurate. The system also helps to ensure that assets are secure and management policy is being followed properly. Its efficient working not only guarantees management as to the reliability of accounting information, independent auditors also rely on system of internal control in determining the timing, nature, and extent of the audit work. Internal control systems are processes aimed at assuring the achievement of an organization's objectives in operational effectiveness and efficiency, reliable financial reporting, and compliance with laws, regulations, and policies (Michelon, Bozzolan, \& Beretta, 2015). Internal control systems begin as internal processes with the positive goal of helping a corporation meet its set objectives (Cunningham, 2004). Indeed, internal control systems are an integral part of any organizations' financial and business policies and procedures. Emphasizing the usefulness of internal 
INTERNATIONAL JOURNAL OF ACADEMIC RESEARCH IN BUSINESS AND SOCIAL SCIENCES Vol. 9, No. 6, June, 2019, E-ISSN: 2222-6990 @ 2019 HRMARS

control systems, Nyakundi et al., (2014), posits that internal control systems can reveal problems associated with lower revenues, and explore links between earnings management and disclosure of material weakness and fraud

\section{Types of Internal Control System}

There are different types of internal control system. Dittenhofer (2001) listed the types of internal controls to include; safeguarding assets, separation of duties, supervision, verification, approval and authorization, documentation and reporting. DiNapoli (1999) discussed the types of internal control to include; directive controls, preventive controls, compensating controls, detective controls, and corrective activities. These types of internal controls are clarified below.

Directive Controls: directive controls are established to ensure compliance with regulations. He asserted that, management must send message that control procedures are very important to promote directive controls compliance. Directive controls helps to identify that an error has occurred but do not prevent errors. Directive controls include activities such as audits, inventory taking, reviews, reconciliations, and variance analysis. Directive controls provides evidence about the effectiveness of preventive controls.

Preventive Control: Preventive controls relate to measures taken by a firm to deter noncompliance with policies and procedures. They are proactive controls that help to prevent a loss. Examples of preventive controls are separation of duties, proper authorization, adequate documentation and physical control over assets.

Compensating Controls: Compensating controls are intended to make up for a lack of controls elsewhere in the system. For example, firms with an electronic database could maintain a hard copy of the client list in the office library. Such a list would compensate for downtime in electronic systems and difficulties in locating client names in an electronic system. While the list would have to be reprinted from time to time to add new clients would mitigate some of the obsolescence that exists with hard copies.

Detective Controls: Detective controls are set up to discover errors after they have happened. Nonetheless, preventive controls are more critical than detection of occurred errors. Also detective controls don't work legitimately with the absence of penalties.

\section{Principles of Good Internal Control System}

The institutionalization of an internal control system are not haphazardly hence must follow certain principles if it must contribute positively to the achievement of organizational goals. These principles according to Ravinder Kumar, Virender Sharma (2005) includes:

* A well-designed accounting system should be in operation. Financial and accounting operations must be separated, that is, handling of cash and the recording of the movement thereof should be done by different persons.

* Responsibility for the performance of the job must be clearly stated so that there remains no room for doubt or confusion subsequently. To achieve this clear-cut and well-conceived organization structure should be established. 
INTERNATIONAL JOURNAL OF ACADEMIC RESEARCH IN BUSINESS AND SOCIAL SCIENCES

Vol. 9, No. 6, June, 2019, E-ISSN: 2222-6990 @ 2019 HRMARS

* Too much confidence should not be pinned in one individual. Nearly all frauds are committed by 'trusted' officials are employees. It is interesting to note that frauds have acquired owing to their being trusted.

* Rotation principle relating to transfer of an employee from one job to another should be the inflexible guiding rule. This is effective safeguard against collusion and is recognized as

an important canon of sound organization.

* Mechanization of the work wherever feasible and practicable, should be resorted to. Mechanical devices such as cash register, recording time clocks, calculation machines, etc should be introduced.

* The work should be so arranged that work done by one employee could be promptly checked by another independent employee such continuous and constant checking stimulates moral control and also the error and the frauds cannot go undetected.

* The arrangement of the work should be in such a manner that written record of the role played by each employee should be maintained and the work should pass through several hands in a well-defined manner.

* Clear and well-defined rules should be laid down and practically followed relating to dealing of the cash, ordering, receiving and issuing goods etc. Instructions should be in writing in the form of accounting manuals.

* Employees must be in bond so that the tempted employee will be deterred from committing fraud and employer being protected.

* Although not a substitute for protective financial internal control, yet existence of an efficient internal auditing staff is an important element of an effective internal control system.

\section{Theoretical Review}

This study is theoretically supported with the system

The Systems Theory: The systems theory was developed by Kaufmann 1966 to explain the historical development as a vibrant process. According to Amagoh (2008), a system consists of other subsystems whose integration and interdependence move toward an equilibrium within a larger system. Therefore, this theory is all about how systems integrate to a broad range of systems. The systems perspective holds that to fully comprehend function of entire system, the integration among different components or individual units have to be understood. The internal control system covers all relevant areas of an entity and help in creating a properly organized and controlled unit (Cheruiyot, 2014). The theory offers powerful tools to analyze systems of internal control and to understand interactions since an effective system of internal control is an integrated system with interrelated components, supporting principles and attributes (Ayagre, Ishmael \& Nartey, 2014).

\section{Methodology}

In this study, data was generated majorly from primary source using researchers designed five point likert scale questionnaire. The study adopted descriptive design and drew its sample from five selected small and medium scale enterprises from the major industrial hubs of Anambra State (Awka, Nnewi and Onitsha). Purposive sampling technique was used to select a sample of 83 members of 
INTERNATIONAL JOURNAL OF ACADEMIC RESEARCH IN BUSINESS AND SOCIAL SCIENCES

Vol. 9, No. 6, June, 2019, E-ISSN: 2222-6990 (C) 2019 HRMARS

staff from a combined population of 215 members of staff. In testing the hypotheses, the researchers used Mannwhitney Wilcoxon rank test statistical technique with the aid of 23.0 versions of statistical package for social sciences (SPSS)

\section{Results}

$\mathbf{H}_{01}$ : Internal control system does not have significant effect on the operational efficiency of

NPAR TESTS

SMEs

/M-W= ICSandOE BY RANKS(5 1)

/STATISTICS=DESCRIPTIVES

/MISSING ANALYSIS.

\begin{tabular}{|c|c|c|c|c|c|}
\hline & & & $\begin{array}{c}\text { Std. } \\
\text { Deviation }\end{array}$ & $\begin{array}{c}\text { Minimu } \\
\mathrm{m}\end{array}$ & $\begin{array}{c}\text { Maximu } \\
\mathrm{m}\end{array}$ \\
\hline ICSandOE & 25 & 17.0400 & 9.27128 & .00 & 37.00 \\
RANKS & 25 & 3.0000 & 1.44338 & 1.00 & 5.00 \\
\hline
\end{tabular}

Test Statistics $^{\mathrm{a}}$

\begin{tabular}{|l|c|}
\hline & ICSandOE \\
\hline Mann-Whitney U & .000 \\
Wilcoxon W & 15.000 \\
Z & -2.611 \\
Asymp. Sig. (2-tailed) & .009 \\
Exact Sig. [2*(1-tailed Sig.)] & $.008^{\mathrm{b}}$ \\
\hline
\end{tabular}

a. Grouping Variable: RANKS

b. Not corrected for ties.

Finding: the finding from hypothesis one shows that the effect of internal control system on operational efficiency is positive and significant. The $U$ value in the test statistic table above is .000 which is far lower than the 0.05 level of significance hence the alternate hypothesis was accepted in place of the null

$\mathbf{H}_{\mathbf{0 2}}$ : Internal control system does not have significant effect on cost leadership of SMEs

NPAR TESTS

/M-W= ICSandCL BY RANKS(5 1)

/STATISTICS=DESCRIPTIVES

/MISSING ANALYSIS. 
INTERNATIONAL JOURNAL OF ACADEMIC RESEARCH IN BUSINESS AND SOCIAL SCIENCES Vol. 9, No. 6, June, 2019, E-ISSN: 2222-6990 @ 2019 HRMARS

Descriptive Statistics

\begin{tabular}{|l|r|r|r|r|r|}
\hline & & & \multicolumn{1}{|c|}{$\begin{array}{c}\text { Std. } \\
\text { Deviation }\end{array}$} & $\begin{array}{c}\text { Minimu } \\
\mathrm{m}\end{array}$ & $\begin{array}{c}\text { Maximu } \\
\mathrm{m}\end{array}$ \\
\hline ICSandCL & 25 & 16.6400 & 9.95774 & .00 & 34.00 \\
RANKS & 25 & 3.0000 & 1.44338 & 1.00 & 5.00 \\
\hline
\end{tabular}

Test Statistics ${ }^{\mathrm{a}}$

\begin{tabular}{|l|c|}
\hline & ICSandCL \\
\hline Mann-Whitney U & .000 \\
Wilcoxon W & 15.000 \\
Z & -2.712 \\
Asymp. Sig. (2-tailed) & .007 \\
Exact Sig. [2*(1-tailed Sig.)] & $.008^{\mathrm{b}}$ \\
\hline
\end{tabular}

a. Grouping Variable: RANKS

b. Not corrected for ties.

Finding: the SPSS output of the test statistic above shows that internal control system has significant effects on the cost leadership of SMEs. The output shows that $U=.000$, while 0.05 is the level of significance. The researchers therefore accepted the alternate hypothesis and rejected the null

\section{Conclusion}

The goal(s) attainment and sustainability of SMEs is largely dependent on optimal resource application. This study conclude that to generate such optimality, an internal mechanism that ensures that waste of all sorts (financial and non financial) are reduced to the barest minimum while striving to increase revenue inflow must be entrenched in SMEs; by so doing they can achieve both operational efficiency and cost leadership which can be boosters to their financial capabilities

\section{Recommendations}

From the findings and conclusion above, the paper recommend as follows;

i. SMEs should establish appropriate control environment that takes into cognizance the peculiarities in their industry

ii. Internal control should be fused into the overall strategies of SMEs, this will facilitate monitoring and prompt reporting of changes in their cost drivers for appropriate managerial decision and actions

\section{References}

Amudo, A., \& Inanga, E. L. (2009). Evaluation of Internal Control Systems: A case study from Uganda, International Research Journal of Finance and Economics, ISSN1450-2887

Amagoh, F. (2008). Perspectives on Organizational Change: Systems and Complexity Theories. The Innovation Journal: The Public Sector Innovation Journal, 13(3), 1-14 
INTERNATIONAL JOURNAL OF ACADEMIC RESEARCH IN BUSINESS AND SOCIAL SCIENCES

Vol. 9, No. 6, June, 2019, E-ISSN: 2222-6990 (C) 2019 HRMARS

Ayagre, P., Ishmael A., and Nartey, J. (2014). The effectiveness of Internal Control Systems of banks: The case of Ghanaian banks/l, International Journal of Accounting and Financial Reporting, Vol. 4, No. 2, Pp 377-389

Cheruiyot, S. K. (2014). Effectiveness of Systems of internal control in Safeguarding Inventory: A Case Study of Rift Valley Institute of Science and Technology. Unpublished MBA Project. Kabarak University, Kenya

Cunningham, L. A. (2004). The appeal and limits of internal controls to fight fraud, terrorism and other ills. Journal of Corporation Law, 29(2), 267-337.

DiNapoli, T. P. (1999), Standards of Internal control in New York State Government. www.d/NewYorkStateComptroller.htm.

Dittenhofer, M. (2001). Internal auditing Effectiveness: An expansion of present methods, Managerial auditing Journal, Vol. 6 No 8, pp. 443-450.

Ehiedu, V. C., and Ogbeta, M. (2014). An Investigation into the Internal Control System in the Banking Industry (A Study of Some Selected Banks in Asaba, Delta State) European Journal of Business and Management Vol.6, No.9, 2014 www.iiste.org

Mawanda, S. P., (2008). Effects of internal control systems on financial performance in an institution of higher learning in Uganda: A case of Uganda Martyrs University, Unpublished thesis, Uganda Matyrs University

Michelon, G., Bozzolan, S., \& Beretta, S. (2015). Board monitoring and internal control system disclosure in different regulatory environments. Journal of Applied Accounting Research, 16(1), 138-164. doi:10.1108/JAAR-03-2012-0018

Nyakundi, D. O., Nyamita, M. O., \& Tinega, T. M. (2014). Effect of internal control systems on financial performance of small and medium scale business enterprises in kisumu city, kenya. International Journal of Social Sciences and Entrepreneurship, 1 (11), 719-734.

Ravinder, K., and Virender, S. (2005). Auditing: Principles and Practices, Prentice Hall, India

Reid, K., \& Ashelby, T. (2002). The Swansea Internal Quality Audit Processes Quality Assurance in Education

Rick, H., (2005). Principles of auditing Pearson Education Limited.

Schroy, J. (2010). The Basics of Internal Controls\|, Capital Flow Watch, Vol. 2, pg 12-13 